\title{
Paediatric Surgery Training in South Africa: Trainees' Perspectives
}

Authors: $\quad$ Uzair Jooma ${ }^{a}$, Alp Numanoglua, Sharon Cox ${ }^{a}$

a Department of Paediatric Surgery, Red Cross War Memorial Children's Hospital, University of Cape Town, Cape Town, South Africa

\section{Affiliation Address:}

Department of Paediatric Surgery, $6^{\text {th }}$ floor of the Institute of Child Health (ICH) building, Red Cross War Memorial Children's Hospital, Klipfontein Road, Rondebosch, 7700, Cape Town, South Africa

\section{Corresponding Author:}

Uzair Jooma

Email: ujooma@gmail.com

Phone: 0721827296

Fax: 0216586632

Postal Address:

Department of Paediatric Surgery, $6^{\text {th }}$ floor of the Institute of Child Health (ICH) Building, Red Cross War Memorial Children's Hospital, Klipfontein Road, Rondebosch, 7700, Cape Town, South Africa

Acknowledgements: None 
The copyright of this thesis vests in the author. No quotation from it or information derived from it is to be published without full acknowledgement of the source. The thesis is to be used for private study or noncommercial research purposes only.

Published by the University of Cape Town (UCT) in terms of the non-exclusive license granted to UCT by the author. 


\section{DECLARATION}

I, ...Uzair Jooma......, hereby declare that the work on which this dissertation/thesis is based is my original work (except where acknowledgements indicate otherwise) and that neither the whole work nor any part of it has been, is being, or is to be submitted for another degree in this or any other university.

I empower the university to reproduce for the purpose of research either the whole or any portion of the contents in any manner whatsoever.

Signature: Signed by candidate

Date: $\quad \ldots 28 / 04 / 2021$ 


\begin{abstract}
Purpose:

There is very little documented evidence regarding the training of paediatric surgeons in South Africa since its inception as a formal speciality in 2007. This study aims to assess South African paediatric surgical trainees' perspectives regarding their training.
\end{abstract}

\title{
Methods:
}

A prospective study was conducted via an emailed electronic survey. The sample population included all current paediatric surgical trainees in South Africa. The questionnaire covered the trainees' demographics, exposure to different aspects of paediatric surgery, extent of after-hours clinical service, self - reported surgical competency and consultant supervision.

\section{Results:}

Forty one (95\%) out of 43 trainees responded to the survey with 29 (71\%) being female. Reported training deficits included lack of exposure to burn care in 12 trainees (30\%), no urology exposure in 8 $(20 \%)$, no paediatric trauma or minimally invasive surgery exposure in $6(15 \%)$. Eighteen trainees (44\%) reportedly worked more than 65 hours per week with clinical responsibilities being the biggest hindrance to attending academic teaching. Trainees were more comfortable performing open procedures compared to laparoscopic but most respondents felt adequately supervised.

\section{Conclusion:}

There exists a significant heterogeneity amongst the different training institutions with protected academic time and exposure to burns, urology and minimally invasive surgery remaining major obstacles in training.

Keywords: paediatric surgery training, trainees' perspectives 


\section{Paediatric Surgery Training in South Africa: Trainees' Perspectives}

\section{Introduction}

South Africa is considered to be an Upper Middle Income Country and has undergone significant political and social transformation since the abolishment of Apartheid in 1994[1]. This has impacted tremendously on the healthcare system and the burden of disease it services. It is estimated that about $85 \%$ of children in Africa under the age of 15 will require some kind of surgical intervention and of note is that $29 \%$ of South Africa's population consists of children less than 14 years of age[2]. Historically, however, children with surgical diseases have taken a lower priority in terms of national health policy. This is due to the significant HIV epidemic and other communicable diseases taking priority as relates to both policy and available resources[3].

The current national average of one paediatric surgeon per 2,6 million children is well below those of high income countries[4]. This figure does not reflect the unequal distribution of resources, with 4 of the country's 9 provinces having no specialist paediatric surgeon up until 2018[4]. Currently there are 3 provinces with no specialist paediatric services present. This leaves 4,5 million children with limited access to these specialised services[4]. Paediatric surgery as a speciality in South Africa is relatively young with it only being recognised as a sub-speciality in 1984 and gaining formal recognition by the Health Professional's Council of South Africa (HPCSA) as a separate specialty in 2007[5]. With the advent of the speciality, came the need to develop a standardised training programme, which started in 1984, and accompanied the establishment of specialised paediatric surgical services across the country[5].

Trainees are currently required to undergo a minimum 5 year training period, usually at least 1 year of training in general surgery, with specific rotations in Trauma Surgery and the Intensive Care Unit followed by taking the Fellowship of the College of Surgeons intermediate examination, and then 4 years in an accredited paediatric surgery training facility, of which there are 8 across the country[6]. A mandatory Masters of Medicine (MMed) research dissertation and an exit examination, the Fellowship of the College of Paediatric Surgeons Final Examination, are required to be completed at the end of this period in order to qualify as a specialist paediatric surgeon[6]. Eligibility for and conduct of the examination is governed by the College of Medicine of South Africa (CMSA), while final registration as a specialist Paediatric Surgeon is accredited by the HPCSA.

Very little is known about the adequacy of paediatric surgery training in South Africa. A recent study on the perceptions of the adequacy of training of South African general surgery trainees highlights the challenges they face[7]. The majority of general surgery trainees felt they had insufficient operative supervision and protected academic time due to overwhelming clinical duties[7]. This is in keeping with training in a developing world context with less structured training programmes and less protected academic time due to a shortage of health care workers with burgeoning clinical needs[7, 8].

Since the advent of the four-year formal paediatric surgical training part of the programme, there has been no assessment of paediatric surgery trainees' perceptions and views on their training, nor has there been any official policy indicating the need for training in specific associated disciplines 
such as burns or trauma in order to qualify for the examination. This has been particularly important with the recent introduction of pre-requisites for entrance to the final examination by the CMSA which includes the completion of a Laparoscopic Skills competency certificate[6]. Thus training in minimally invasive surgeries is deemed, by the examining body, to be a very important factor in the training of paediatric surgical trainees. This study looks to identify gaps in training as well as the perceptions of trainees in South Africa with regards to the paediatric surgical training plan currently in place within their institutions.

\section{Methods}

Ethics approval was obtained through the University of Cape Town's Human Research Ethics Committee (HREC744/2019). This was a quantitative prospective study conducted via a 50 item electronic survey using the platform SurveyMonkey@ which was emailed to all trainees nationally. It was designed according to the Checklist for Reporting Results of Internet E-Surveys [9] and adapted from a previous study entitled "Registrar perceptions on general surgical training in South Africa: A report by the South African Society of Surgeons in Training (SASSiT)" with the permission from the primary author[7]. It underwent face validation by multiple Professors in Paediatric Surgery involved in training of paediatric surgeons in South Africa. The study was conducted from November 2019 to February 2020. Informed consent was obtained and there was no remuneration for participation.

The sample population included all current university registered paediatric surgical trainees in South Africa excluding the primary researcher with the sample size being 43 . This included supernumerary trainees who were part of the 4 year post basic training programme who would be eligible to write the final CMSA Paediatric Surgery exam. Most questions were in the form of multiple choice answers or multiple tick box selections. Open ended question were also asked to allow trainees to further express their views. Supernumerary trainees or international fellows on shorter programs who were not eligible to write the final examinations were excluded from the research.

The survey consisted of 6 different sections:

a) Demographics: Demographic data collected included age, gender, race, year of study and training institution. Institutional data were collected primarily for assessing data completion and representation purposes rather than institutional comparisons.

b) Exposure in Paediatric Surgery: Trainees were questioned on their exposure to different aspects of paediatric surgery, either on a day to day basis or as part of a formal rotation. These aspects included paediatric burns, trauma, urology, oncology and minimally invasive surgery.

c) Clinical workload and surgical competency: This section dealt with the number of afterhours clinical work trainees performed per month, number of surgical cases involved in per month and satisfaction with exposure to minimally invasive techniques. Trainees were also asked if they were able to operate, as the primary surgeon, on certain index paediatric surgical procedures at the appropriate year of their training. The index procedures were formulated in discussion with senior Paediatric Surgery Professors involved in the teaching of paediatric surgery trainees and were relevant to the South African context.

d) Academic programme: This section covered the academic programme within the institution. It covered the number of hours of scheduled academic time, barriers to attending these, 
preparedness for the final Paediatric Surgery exam and supervision regarding the research component (MMed) of their training.

e) Consultant supervision: This section dealt with consultant supervision in terms of operative procedures, outpatient management, inpatient management and after-hours service.

f) General perceptions: This section covered the trainees' general perceptions of their training in terms of whether they felt prepared for independent practice and which sector they would practice in (private, public or both) once they had completed their training.

Using Raosoft, a sample size of 39 respondents was required to attain a confidence interval of $95 \%$ with a $P<0.05$. Survey results were entered into Microsoft Excel and a cumulative descriptive analysis was performed. Results were analysed in an aggregate fashion so as to ensure respondents anonymity and confidentiality.

\section{Results}

The response rate for the survey was $95 \%$ with 41 of the 43 trainees responding to the survey. The completion rate was $98 \%$ with a single respondent omitting to fill out the last section of the survey. Responses were received from trainees in all the paediatric surgical training facilities in South Africa.

\subsection{Demographics}

The demographic detail for the sample population is represented in Table 1. The majority of trainees were female $(71 \%)$ of black ethnicity (54\%) and were between the ages of $30-39$ years (76\%). There was an adequate spread of trainees throughout the different years of training with the majority (29\%) being in their third year of the paediatric surgical training programme. 
Table 1: Demographic details of participants

\begin{tabular}{|ll|}
\hline Demographic Variable & Number of respondents (\%) \\
\hline Gender & $12(29 \%)$ \\
Male & $29(71 \%)$ \\
Female & $41(100 \%)$ \\
Total & \\
Age (years) & $5(12 \%)$ \\
$20-29$ & $31(76 \%)$ \\
$30-39$ & $5(12 \%)$ \\
$40-49$ & $41(100 \%)$ \\
Total & \\
Ethnicity & $8(19 \%)$ \\
White & $22(54 \%)$ \\
Black & $2(5 \%)$ \\
Coloured & $4(10 \%)$ \\
Asian & $2(5 \%)$ \\
Prefer not to answer & $3(7 \%)$ \\
Other & $41(100 \%)$ \\
Total & \\
Year of Training & $10(24 \%)$ \\
$1^{\text {st }}$ & $10(24 \%)$ \\
$2^{\text {nd }}$ & $12(29 \%)$ \\
$3^{\text {rd }}$ & $6(15 \%)$ \\
$4^{\text {th }}$ & $2(5 \%)$ \\
$5^{\text {th }}$ & $1(3 \%)$ \\
$6^{\text {th }}$ & $41(100 \%)$ \\
Total & \\
\hline
\end{tabular}

\subsection{Exposure}

Trainees had the following exposures to the different aspects of paediatric surgery as demonstrated in Table 2. 'Exposure' includes either a formal rotation or day to day management of these patients.

Table 2: Exposure to different aspects of paediatric surgery

\begin{tabular}{|llll|}
\hline Rotations & Exposure (\%) & No Exposure(\%) & $\begin{array}{l}\text { Total } \\
\text { Respondents(\%) }\end{array}$ \\
\hline Burns & $29(71 \%)$ & $12(29 \%)$ & $41(100 \%)$ \\
Urology & $33(80 \%)$ & $8(20 \%)$ & $41(100 \%)$ \\
Trauma & $35(85 \%)$ & $6(15 \%)$ & $41(100 \%)$ \\
Oncology & $35(90 \%)$ & $4(10 \%)$ & $39(100 \%)$ \\
Minimally Invasive & $33(85 \%)$ & $6(15 \%)$ & $39(100 \%)$ \\
Surgery & & & \\
\hline
\end{tabular}




\subsection{Clinical Workload and Surgical Competency}

Thirty two (78\%) respondents performed between 5-7 after hours calls per month while 9 (22\%) performed more than 8 . When questioned regarding the number of after hours worked this equated to 13 trainees working between $65-70$ hours per week while 5 trainees worked more than 70 hours on site per week.

In terms of self reported surgical competency trainees were asked about index paediatric surgical procedures and whether they were able to perform them independently, unless otherwise specified, at the appropriate year of training (see Table 3).

\section{Table 3: Self reported surgical competency to index procedures}

\begin{tabular}{|c|c|c|c|}
\hline Year of Trainee & $\begin{array}{l}\text { Number of Trainees } \\
\text { able to perform }\end{array}$ & $\begin{array}{l}\text { Number of Trainees } \\
\text { not able to perform }\end{array}$ & Total \\
\hline \multicolumn{4}{|l|}{$1^{\text {st }}$ or $2^{\text {nd }}$ year trainee } \\
\hline Laparoscopic/open appendectomy & 33 & 8 & 41 \\
\hline $\begin{array}{l}\text { Neonatal Inguinal Hernia } \\
3^{\text {rd }} \text { year trainee }\end{array}$ & 34 & 7 & 41 \\
\hline $\begin{array}{l}\text { Neonatal Laparotomy for NEC } \\
4^{\text {th }} \text { year trainee }\end{array}$ & 19 & 2 & 21 \\
\hline $\begin{array}{l}\text { Laparotomy for neonatal } \\
\text { emergency (eg intestinal } \\
\text { atresia/midgut volvulus) - } \\
\text { supervised }\end{array}$ & 18 & 0 & 18 \\
\hline $\begin{array}{l}\text { Laparoscopic Nissen } \\
\text { Fundoplication }\end{array}$ & 8 & 10 & 18 \\
\hline
\end{tabular}

There were 18 respondents to the question of index surgical procedures for $4^{\text {th }}$ year trainees. Two of the respondents were second year trainees, 7 were third year trainees and 9 were in their fourth year or more. All of the respondents to this question were comfortable performing a neonatal laparotomy however, only 5 of the fourth year trainees were able to perform a complete Laparoscopic Nissen Fundoplication.

\subsection{Academic Programme}

The number of hours per week of scheduled formal teaching is represented in Table 4 below:

Table 4: Number of hours of scheduled teaching per week

\begin{tabular}{|ll|}
\hline No. of hours & No. of respondents \\
\hline $0-2$ & $9(22 \%)$ \\
$3-4$ & $26(63 \%)$ \\
$5-6$ & $2(5 \%)$ \\
$>6$ & $4(10 \%)$ \\
Total & $41(100 \%)$ \\
\hline
\end{tabular}


Only $7(17 \%)$ respondents were able to attend all scheduled formal academic teaching. The biggest hindrance to attending teaching was clinical responsibilities of the surgical unit with 38 (93\%) trainees identifying this as the main reason. 13 (32\%) respondents felt they had sufficient protected academic time to complete their Masters of Medicine research project. 33 (81\%) respondents felt they had sufficient teaching to prepare them for their final exit exam.

\subsection{Consultant Supervision}

Table 5 represents whether trainees felt adequately supervised by consultants in the following spheres of work:

Table 5: Consultant supervision satisfaction

\begin{tabular}{|llll|}
\hline Sphere of Work & $\begin{array}{l}\text { Adequately } \\
\text { supervised }\end{array}$ & $\begin{array}{l}\text { Inadequately } \\
\text { supervised }\end{array}$ & Total \\
\hline $\begin{array}{l}\text { Operative procedures } \\
\text { Out-patient }\end{array}$ & 32 & 9 & 41 \\
$\begin{array}{l}\text { Management } \\
\text { In-patient }\end{array}$ & 31 & 19 & 40 \\
$\begin{array}{l}\text { Management } \\
\text { After-hours service }\end{array}$ & 34 & 10 & 41 \\
\hline
\end{tabular}

Twenty-one trainees (53\%) felt they would not be prepared for independent practice once their training was complete. Thirty-four (85\%) trainees felt an additional year of training time as a junior specialist paediatric surgeon would better prepare them for independent practice.

\section{Discussion}

There still remains tremendous inequality in skills and economic empowerment amongst the previously disadvantaged race and gender groups in post-Apartheid South Africa. Prior to 1984 there was no formalised training programme or exit examination for those training in Paediatric Surgery. The period between 1984 and 2007 saw it being recognised as a sub-specialty with trainees required to undergo a 2 year fellowship following the completion of a 4 year general surgery speciality[5]. In 2007 , with advent of it being recognised as stand-alone speciality, the 4 year training programme in paediatric surgery was developed which allowed trainees to focus for a longer period of time on surgical training in children[5]. The paucity of published data around the formal training of paediatric surgeons in South Africa is understandable given that it is 13 years old and consists of 44 trainees in total. This is in comparison to the General surgery fellowship which is over 65 years old and consists of over 240 trainees nationally[7, 10].

This study found that $71 \%$ of current trainees are female compared to the current specialist body of $31 \%[4]$. Specialist paediatric surgeons of black ethnicity currently registered with the HPCSA make up around $19 \%$ of paediatric surgeons in South Africa. However, more than half (55\%) of the current paediatric surgical trainees were of black ethnicity. This is encouraging to note as both gender and racial inequalities from the past are slowly being addressed and transformation is taking place. 
South Africa has a low density of paediatric surgeons in proportion to the burden of disease and thus they have to cover many different facets of surgical care to children including urology, burns and trauma[4]. It is concerning that $20 \%$ of trainees do not get any exposure to paediatric urology during their training especially considering there is no formally developed paediatric urology subspecialty in South Africa. Certain centres choose to address this gap by rotating trainees through other centres where paediatric urology is offered. With around 3200 patients, both adults and children, requiring hospitalisation for burn injuries annually in South Africa and paediatric surgeons managing $33 \%$ of the paediatric burns units nationally it is also worrisome that $29 \%$ of trainees have no exposure to burn care during their training[11, 12]. The burden of paediatric trauma in South Africa is significant with it accounting for an estimated 22.2 deaths per 100000 children and only a single dedicated paediatric trauma unit nationally[13, 14]. Paediatric surgeons have a significant involvement in the management of paediatric trauma yet $15 \%$ of trainees do not get any exposure to paediatric trauma. These numbers highlight the heterogenicity amongst the different training institutions. The lack of exposure to urology, burns and trauma is not in line with the CMSA syllabus or the examination blueprint that suggests that $12 \%$ of the final examination consists of urological questions, $3 \%$ burns related questions and $5 \%$ relating to paediatric trauma[15].

In terms of clinical workload it is pertinent to note that $44 \%$ of trainees work more than 65 hours per week which is comparative to the average of 67 hours worked by General Surgery trainees in South Africa[16, 17]. This is above their contracted 60 hours per week average, as well as above the regulated 48 hour work week for European Trainees however, less than the 80 hour work week stipulated for trainees in the United States of America (USA)[18]. Working hours for trainees in South Africa are not strictly regulated and this seems to impact on their academic and research time. Ninety three percent of paediatric surgical trainees surveyed identified clinical service responsibilities as the biggest hindrance to attending academic activities with only $17 \%$ being able to attend all academic activities. This is similar to the barriers facing South African General Surgery trainees with $95 \%$ of them identifying clinical responsibilities as the biggest barrier to attend academic teaching[7]. It is also reflected in the fact that only $32 \%$ of respondents felt they had sufficient protected academic time to complete their MMed research project. It is not known whether this increased clinical workload translates into higher operative exposure as there is currently no published data on the operative logbooks of paediatric surgeons in South Africa.

With $61 \%$ of trainees not satisfied with their training in minimal invasive techniques and $15 \%$ reporting no exposure to minimally invasive surgery it is not surprising that both junior and senior trainees are much more comfortable with performing open procedures such as neonatal laparotomies (100\%) compared to laparoscopic procedures such as a Nissen Fundoplication (56\%). This is in keeping with the perceptions of South African General Surgery trainees with $63 \%$ of them reporting to have not received adequate training in minimally invasive surgery[7]. The number of minimally invasive cases performed by trainees is increasing in developed countries such as the USA and Canada and an assessment of surgical logbooks might provide a better insight into minimally invasive training in South Africa[19]. Barriers to minimally invasive training would also need to be explored with previous studies reporting lack of resources and necessary skills as the main issues in a South African context[7]. It is also important to note that different training centres have differing entry requirements for trainees prior to entering their paediatric surgery training programmes. Some centres accept trainees with no previous surgical experience or completion of primary/intermediate surgical examinations, while others require their trainees to have a few years 
of general surgical experience together with completion of their intermediate exams. This might account for discrepancy in surgical competency amongst trainees at the same year of their paediatric surgical training.

Despite the significant clinical burden the majority of trainees felt adequately supervised by specialists with regards to operative procedures, in-patient management and after hour's service all of which are important teaching opportunities[20]. However almost half of respondents (53\%) felt inadequately supervised with outpatient management and this could be a reflection of the high clinical, administrative and undergraduate teaching roles of specialist paediatric surgeons. Given the significant resource restrictions together with the high disease burden on the South African Public Health sector it is encouraging to note that $95 \%$ of trainees intend to remain within the public sector either exclusively or work in both public and private sectors. This is in keeping with a previous study performed on paediatric surgeons in South Africa[4]. Taking into account that there are only 14 specialist public sector posts nationally, a large proportion of qualified trainees are either forced to emigrate or work exclusively in private practice[4]. Another pressing concern is that only half of trainees felt they would be ready for independent practice once their formal training is completed with a lack of operative time and training period that is too short being some of the key reasons cited by this study.

Possible recommendations to improve clinical training would include rotations through different training institutions to cover gaps in exposure at the base institution. This may be a more workable solution than adding these clinical services to the institutions not providing them. Lengthening of the formal paediatric surgery training period from 4 to 5 years or an additional year of Junior Consultant time once training is completed would be beneficial. This would allow qualified trainees to work under senior supervision to build confidence and skills which would improve exposure to major cases as well as increase more senior staffing levels resulting in increased supervision for junior trainees. The majority of trainees (85\%) supported this view. Working towards a competency based training curriculum may also be of benefit.[21]

\section{Conclusion}

The training of Paediatric Surgeons in South Africa is representative of the challenges facing the healthcare systems of low to middle income countries with a burgeoning clinical load and service delivery being balanced against academic teaching and supervised training. It is also quite evident that there is a significant heterogeneity amongst the different training institutions. Protected academic time and exposure to burns, urology and minimally invasive surgery remain major obstacles in training. This study has highlighted the need to critically look at the gaps in training and it is hoped that it will stimulate conversation and action aimed at improving training across the highlighted areas of concern.

\section{Limitations and Future Research}

This study is based on the self-reported perceptions of trainees and does not represent observed practice or the reports from training academic supervisors. Self reported surgical competency does not necessarily translate into actual surgical competency so a review of operational logbooks would serve well in defining this together with giving an indication of the case-load. 


\section{Declaration}

7.1. Conflict of interest

The authors declare that they have no conflict of interest.

7.2. Funding

This research did not receive any specific grant from funding agencies in the public, commercial, or not-for-profit sectors.

7.3. Ethics Approval

The questionnaire and methodology for this study was approved by the Human Research Ethics committee of the University of Cape Town (HREC744/2019).

7.4. Consent to participate

Informed consent was obtained from all individual participants included in the study.

\section{References:}

1. Dell, A. and D. Kahn, Surgical resources in South Africa: an international comparison and deficit calculation. World journal of surgery, 2018. 42(2): p. 541-548.

2. Toobaie, A., et al., Pediatric surgical capacity in Africa: Current status and future needs. $J$ Pediatr Surg, 2017. 52(5): p. 843-848.

3. Lehohla, P., Statistics South Africa Annual Report 2013/2014, S.S. Africa, Editor. 2014, Statistics South Africa: South Africa.

4. Dell, A., et al., Pediatric surgeon density in South Africa. J Pediatr Surg, 2018. 53(10): p. 20652071.

5. Rode, H. and A.J. Millar, Our surgical heritage: the role of the Department of Paediatric Surgery in the development of paediatric surgery in Cape Town, in Africa, and around the world. South African Medical Journal, 2012. 102: p. 409-11.

6. Africa, T.C.M.o.S., Regulations for Admission to the Fellowship of the College of Paediatric Surgeons of South Africa FC Paed Surg(SA), T.C.o.M.o.S. Africa, Editor. 2018.

7. Patel, N., et al., Registrar perceptions on general surgical training in South Africa: A report by the South African Society of Surgeons in Training (SASSiT). South African Journal of Surgery, 2018. 56(2): p. 10-14.

8. Patel, N. and J. Loveland, A perspective on paediatric surgical training: opportunities and challenges. South African Journal of Surgery, 2017. 55(4). 
9. Eysenbach, G., Improving the quality of Web surveys: the Checklist for Reporting Results of Internet E-Surveys (CHERRIES). Journal of medical Internet research, 2004. 6(3): p. e34.

10. Degiannis, E., et al., Surgical Education in South Africa. World Journal of Surgery, 2008. 33(2): p. 170-173.

11. Allorto, N., S. Wall, and D. Clarke, Quantifying capacity for burn care in South Africa. Burns Open, 2018. 2(4): p. 188-192.

12. Rode, H., A. Berg, and A. Rogers, Burn care in South Africa. Annals of burns and fire disasters, 2011. 24(1): p. 7.

13. Herbert, H.K., et al., Patterns of pediatric injury in South Africa: an analysis of hospital data between 1997 and 2006. Journal of Trauma and Acute Care Surgery, 2012. 73(1): p. 168-174.

14. Manchev, V., et al., The incidence, spectrum and outcome of paediatric trauma managed by the Pietermaritzburg Metropolitan Trauma Service. The Annals of The Royal College of Surgeons of England, 2015. 97(4): p. 274-278.

15. Africa, C.o.M.o.S., FC Paed Surg(SA) Final Exam: Blueprint, C.o.M.o.S. Africa, Editor.

16. Kong, V., J. Odendaal, and D. Clarke, Surgical resident working hours in South Africa. South African Journal of Surgery, 2015. 53(4): p. 8-10.

17. Vadia, S. and D. Kahn, Registrar working hours in Cape Town. South African Journal of Surgery, 2005. 43(3): p. 62-64.

18. Glomsaker, T. and K. Søreide, Surgical training and working time restriction. British Journal of Surgery: Incorporating European Journal of Surgery and Swiss Surgery, 2009. 96(4): p. 329-330.

19. Cairo, S.B., C.M. Harmon, and D.H. Rothstein, Minimally invasive surgical exposure among US and Canadian pediatric surgery trainees, 2004-2016. J Surg Res, 2018. 231: p. 179-185.

20. Monkhouse, S., Learning in the surgical workplace: necessity not luxury. The clinical teacher, 2010. 7(3): p. 167-170.

21. Beasley, S.W., The challenges facing training in pediatric surgery worldwide. Front Pediatr, 2013. 1: p. 24. 